\title{
PIDGIN AND CREOLE IN ADVERTISING AND MARKETING
}

\section{ThankGod Lolo Raymond and Isaac Eyi Ngulube}

English Department, Rivers State University

Cite this article:

ThankGod L.R., Isaac E.N. (2022), Pidgin and Creole in Advertising and Marketing. British Journal of Mass Communication and Media Research 2(1), 1-13. DOI: 10.52589/BJMCMRTZRJSI8L

\section{Manuscript History}

Received: 20 Nov 2021

Accepted: 10 Dec 2021

Published: 12 Jan 2022

Copyright $\odot 2020$ The Author(s). This is an Open Access article distributed under the terms of Creative Commons AttributionNonCommercial-NoDerivatives 4.0 International (CC BY-NC-ND 4.0 ), which permits anyone to share, use, reproduce and redistribute in any medium, provided the original author and source are credited.
ABSTRACT: The title of this paper is 'Pidgin and Creole in advertising and marketing' in Nigeria. The data for analyses was elicited through recording, transcribing, and translating. The focus of this study is the inconsistencies in spellings and choice of words, which leads to frustration and ambiguities as observed by the target audience in the adverts. Considering the serious nature of the messages they intend to pass across and the cost incurred in designing and airing the adverts, one is worried why a little bit of imagination, creativity and seriousness is not applied in the crafting of the advertisements. We are aware that standard pidgin orthography exists which conforms to the principle of good orthography; organizations and individuals seeking to develop adverts or broadcast in pidgin should consult this document for consistency. Nigerian Pidgin English is already an unauthorized lingua franca; therefore, all efforts should be on the deck to standardize it. We have presented some adverts done in pidgin, analysed them to evince their inadequacies, ambiguities, conflicting messages, poor effects, and argue that although many people are often easily carried along with adverts in pidgin, the message is essentially lost ab initio. Pidgin and creole can only be used nationally, meaning they cannot communicate internationally, or even with neighbouring countries. For this reason, adverts cannot be done in pidgin and creole with the intention of getting international patronage. They are often viewed as low class, grammatically incorrect, and with no wellstructured syntax or phonology, so adverts done in pidgin and creole are often selective. Hence, if the customers are those from the upper class, an advert in pidgin or creole is a wrong move.

KEYWORDS: Pidgin, Creole, Advertising, Marketing, Nigeria 


\section{INTRODUCTION}

Pidgins have been defined as languages with reduced vocabulary and structure which arose in contact situations between speakers who had no language in common and must reach an understanding. Creoles are languages that evolved from pidgins through a nativization process in a speech community and subsequently have native speakers, the former being a lingua franca or a trade language spoken as a second language which developed out of an original pidgin, and as a result of becoming the mother tongue of a community, expanded its resources and functions. An investigation into the origin of pidgins and creoles is tedious because of the absence of independent corroboration of the pidginization process. Modern scholars have amassed a substantial gen on the issue; so, tracing the sketchy and hypothetical history is not really necessary. The origin of pidgin has remained a very controversial issue for quite a long time and in an attempt to explain the origin of pidgins, scholars have advanced two main different competing theories. These are the Monogenetic theory and the Polygenetic theories. According to Loreto Todd (1974), the monogenetic theorist opines that all pidgins have a common origin and essentially the same method of spread, whereas the polygenetic theorist postulates that pidgin of each different community arose from a unique and separate process of creation and development. We will not pursue these arguments further as it is not pertinent to our concern here.

\section{Pidgin Languages around the World}

Currently, speculatively, about sixteen pidgin languages exist around the world. On the other hand, one hundred creole languages are in existence around the world. Recall that pidgins are transitory means of communication. Transitory here means that they only survive for a few decades at the most. This accounts for why there are more creoles than pidgins. Pidgins originate as contact languages, and exist to meet trade needs of those who use it. After a while, their status changes, some developed into creoles, while the remaining fade away gradually. This occurs because the speakers scatter and the dominant language of the area takes over as the language of wider communication.

Of the sixteen pidgins in use today, Chinook Wawa is used in the area of Pacific Northwest, around "Alaska, British Columbia, Washington State, Oregon, Idaho, Montana and North California" (4). This pidgin is derived from Chinook, French and English languages. There are some smidgens of loanwords as superstrate from these European languages. Another pidgin in existence today is Nefamese; it is also called Arunamese. This pidgin is spoken around Arunachal Pradesh in India. It is the lingua franca for the people of "Nyishi, Adi, Apatanai, Khampti, Hill Miri, IduMishimi, Nocte, Wancho, Tagin, Mompa, Zakhring and Bugu" (4). There are communities around the Northeast of India who also speak this pidgin. Hindi speakers are slowly replacing this pidgin with Hindi as a language of wider communication. Liberian Pidgin English is also called Kolokwa or Liberian Kreyol. It is used widely in Liberia as an L2. The population of its users ranges from one million and five hundred thousand to three million speakers. This pidginized English has a dialect known as Kru Pidgin English. It is a language of the Kru fishermen in West Africa.

The next Pidgin English, called Nauruan Pidgin English, is based on "the now extinct Chinese Pidgin English and Melanesian-type pidgins" (4). Nauruan Pidgin English is employed on the "tiny island country of Nauru in the Central Pacific" (5) as a language of wider communication. The settlers in Kenya and Zambia use Swahili pidgin, also called Settler Swahili or simply 
Settla, to expedite verbal interaction between them and the native Swahili speakers. This pidgin grew out of colonialism. We do not know how many people speak this pidgin presently. Fanakalo is a Pidgin Zulu language that originated from colonial activity. South Africa and Zimbabwe are populated by a large number of Fanakalo speakers. This pidgin enables English and Dutch immigrants to talk with the domestic helps, and to accelerate interaction amid the English and Dutch migrants.

A good number of pidginized languages have gone extinct today. The reasons are that the factors that gave birth to them, in the first place, are no longer there. When this occurs, the said pidgin no longer survives. One such pidgin amongst others is Chinglish, also known as the Chinese Pidgin English. This pidgin existed for about three centuries before it went extinct because of preference for the Standard English language by its speakers. Chinese Pidgin English was a trade language between the English, Chinese traders and bureaucrats in Canton.

\section{Creole Languages around the World}

It is estimated that about one hundred creoles exist in the world presently. Here, we delineate the most widely spoken creoles to spice up the extent to which creoles are used around the world today, in order to legitimize it. First, we start by examining English-based creoles, and British sailors and colonialists, who over the 17th nd 18th centuries established trading outposts in the Americans and Africa. These British sailors and colonialists took their language with them for communicative purposes. The unfortunate bit is that the Americans and Africans have their indigenous languages which were inaccessible to these sailors and colonialists. Both parties had to resort to pidgin which later developed into creoles. These creoles are found in Africa, the Caribbean, and the islands of the Pacific Ocean. The ones that have grown into languages of wider communication are our concerns here.

Nigerian Pidgin English (NPE): NPE is spoken by about 30 million first language speakers; it has native speakers in several parts of the country and it has varieties in places like Diobu in Port Harcourt and Sapele/Warri in Delta State. Many children acquire it from childhood. Although non-linguists still think of NPE as a pidginized form of English, linguists know that NPE is fast creolizing. This study focuses on NPE; it is basically an English based creole in spite of the name. Majority of the speakers are non-native speakers, about 40 million of them; it is sometimes called 'Brokin'. As we speak, it is a de facto lingua franca for Nigeria.

Krio: The number of persons who speak Krio in Sierra Leone is about $87 \%$ of the population; this is broken down into 473, 000 first language users and nearly 4 million second language users.

Jamaica Creole: The 3 million speakers of this creole are in Jamaica and its surrounding islands, including those in diaspora. This creole is a mixture of English and Akan language of West Africa.

Cameroonian Creole: The total number of speakers is variously estimated at about 2 million people. The native speakers of this Cameroonian Pidgin English, also called Kamtok, are estimated at about $50 \%$ of the population. Another $50 \%$ of the population speak it as a second language.

Tok Pisin: This pidgin is an amalgamation of English and the indigenous languages of Papua New Guinea. It is said to have well over a million native speakers, and about 4 million second 
language users. It is currently used in their National Assembly for debate and in making laws. It is the official language of the people.

Hawaiian Creole English: The total number of speakers is put at one million, out of which 600, 000 are first language speakers and the remaining 400, 000 speak it as a second language.

Bahamian Creole is a variant of the creole spoken in the Caribbean Islands. It has about 400, 000 native speakers in the Bahamas.

Bajan Creole is spoken in Barbados by about 286, 000 people; hence, it is known as Barbadian creole. English is their official language, comparatively used by only 1,000 people.

\section{Language in Advertising and Marketing}

Experts are of the opinion that marketing is a process that organizations embark on to reach their desired audience. The goals are to establish strong relationships with clients and to get value for money. Marketing is one of the main mechanisms of business administration and commerce. Advertising, on the other hand, is the art of bringing to the fore a message about products. It is a marketing strategic communication, which uses amenably funded impersonal messages to grow the selling of products, services or ideas. People that are engaged in advertising are specifically businesses wanting to increase the sales of their products or services.

Language plays a very critical role in the business of advertising. It is characteristically a language game. According to Coker and Oke (1), the advertising industry is a language community that deploys language creatively and imaginatively. Awonusi (112) asserts that advertising flourishes on competent language skills, which foregrounds significant facets of language usage. Coker and Oke (1) comment that "creative advertising copy messages are products of well thought out and orchestrated linguistic and literary processes". The details in the language of advertising texts are not inadvertent but are carefully crafted "to communicate the right message to the right people at the right time" (3).

Yinka (2010) comments that current research on advertising strategies in Nigeria evinces that advertisers spent huge sums of money to scheme and disseminate their messages to their target audiences with the singular purpose of coaxing them to take a course of action they would otherwise not have embarked upon. He further discloses that the use of language often defines 'the success or failure of any advertising initiative'. Crystal (388) observes that 'it is language which can make or break an advert'. The use of language in advertising has therefore proven to be very fruitful; language is not just a means of communicating ideas but also a tool for accomplishing goal-directed actions (Ngulube 15). We now turn to the thrust of this paper.

\section{Pidgin and Creole in Advertising}

Okwechime (2009) posits that advertising in Nigeria probably dates back to 1928. The United African Company (UAC) was the first company to embark on poster adverts, earning them the title of the 'Poster Monarch of Nigeria' and the particular division of UAC is the West African Publicity Limited (WAPL). According to him, pidgin is actually a late arrival on the advertising scene in Nigeria; its use in advertising dates back to the 1960s. The same Okwechime (2009) speculates that the first pidgin advert in Nigeria is probably the Vono foam mattress captioned 'weke-e, weke-e, na him be vono.' Later, other broadcasting corporations in Nigeria began to 
use pidgin in commercial advertising. Recently, the Nigerian Broadcasting Radio station such as WAZOBIA FM commenced running successful adverts in NPE.

Akintayo (172) avers that NPE has provided the Nigerian advertising media with catchy jingles, quotations, dance tunes, coinages, lexical items, catch phrases, slang and colloquial expressions. All these have led to the expansion and expressiveness of pidgin. Furthermore, he asserts that the Nigerian public have a positive attitude towards pidgin advertisements. This is apparent in the incredible acceptance such advertisements relish among the people.

Dada (41) puts it succinctly avowing that Pidgin English adverts are appreciated by everybody in Nigeria because of their dramatic presentation, humour, and twisted syntax. Although this is an overgeneralization, it is not very far from the truth. To cap it all, Oribhabor (3) states that any advert worth paying attention to must be couched in NPE. Again, this kind of claim has no statistical data to back it up. Elugbe (294) observes that government agencies are just beginning to realise that for any message to get to the grassroots, it must be crafted in NPE.

To say that NPE is very pervasive in the entire nation is an understatement. Yinka (2010) reiterates this idea in his statement that a contact and trade language such as Pidgin English, with its vacillating tones and 'playful imagery' is used by Nigerians of all ages, social classes and persons from different regional origins. Again we observed that this is an overstatement. All Nigerians do not accept pidgin; for some elites, it is a gutter language that is beneath them. It is crystal clear that adverts in pidgin are often very humorous; this enables serious issues to be talked about light-heartedly.

Yinka (2010) further posits that pidgin is 'a cross-cultural medium used in literary creativity' and interactive communication in the Nigerian geographical space. He further illuminates that the potential of NPE is enormous in comparison to that of any of the indigenous Nigerian languages. The reasons, he adduces, are that pidgin aids communication in all parts of Nigeria. In other words, no indigenous language has the demography and/or spread that pidgin has in Nigeria. Furthermore, he reasons that geographical spread is vital for effective advertising, since the language is handy to most Nigerians, predominantly among the 'no-so-literate' members of the Nigerian society. This class of people are in the majority and are effortlessly influenced by hilarious advertisements in pidgin. He also asserts that pidgin is a convenient means of impulsive expressiveness. Many Nigerians believe that pidgin is easy to learn because it has no grammatical rules, no inflections, no standard orthography, no complicated tonal structure and processes, or morphologically reduced in comparison to other Nigerian indigenous languages. Elugbe and Omamor (1991) are of the opinion that "pidgin is probably more widely-spoken in Nigeria than any of the three major languages".

In spite of the very clear advantages of pidgins and creoles over the other Nigerian indigenous languages, they have very serious advertising demerits. One of such demerits is that pidgins and creoles are seriously limited. For instance, they are languages of trade, created for that sole purpose by people who do not understand each other. The point being made here is that creoles when employed in advertising select a particular audience, thus limiting the commodity to that particular set of people. It may be argued that some languages referred to as pidgins today are indeed creoles, derived from earlier pidgins, and in that respect full languages comparable to any other natural languages. Be that as it may, the restriction on pidgins and creoles is almost total and complete. 
Secondly, pidgins and creoles are highly restricted to specific geographical spaces. By way of explication, an advert designed in pidgin for Warri audience in Delta state, Nigeria can hardly appeal to people in other countries of West Africa let alone international audience. In other words, organizations cannot do adverts in pidgin and creole, with the intention of getting international patronage. Pidgin and creole, as observed earlier, are often associated with the lower class, thought of as grammatically incorrect with no well-structured syntax or phonology, therefore beneath the status of the elite class. Hence, adverts in these languages are often choosy, so if the client's target audience are those of the elite class, an advert in pidgin is a wrong move.

\section{Analysis of Adverts}

Globally, industrialists and service suppliers stereotypically function in inundated markets where rivalry is ubiquitous. The condition is the same in Nigeria. To be the best, organizations must produce high-quality goods and services and obligatorily embark on effective advertising so the benefits of their products and services are made manifest to the target audience. This will entice customers to use the services, facilities and merchandise. Of course, this is the quintessence of advertising and marketing. Here, we present some adverts done in pidgin, analyse them to evince their inadequacies, ambiguities, poor effects, and argue that although many people are often easily carried along with adverts in pidgin, the message is essentially lost ab initio.

\section{Airtel Advert}

Airtel's sing along advertisement " 444 is a metaphor" became an instant hit with Nigerians, making it to several top commercial lists at the end of the year. $* 444 \#$ is a single mobile channel code that allows Airtel users to recharge from various bank accounts with a single dial. The ad jingle was an ingenious technique of raising awareness and encouraging people to remember Airtel's USSD short code. The song is energetic, catchy, clear, and simple to sing along to, making it a sensation.

The campaign was broadcast and promoted through advertising and a themed contest on Big Brother Naija Lockdown season six. The advert was done in Pidgin, Igbo, and Hausa, expressing the need for a catchy, danceable, and attractive tune in Pidgin. Omolade Oyetundun was used for the voice over, singing and demonstrating the benefits of using Airtel's USSD code. Artiste Adekunle Gold was chosen as the lead performer for the Yoruba version of the song because of his wide appeal in the South West of Nigeria, and the agency used his song 'Orente' as a reference. The lyrics of the song were created to express quantity, efficiency, precision, and the concept of "Connect," which was used in the Smart CONNECT campaign. Phyno was picked for the Igbo version because of his appeal to those who love captivating music from the South Eastern part of Nigeria. 'Father-father', one of his songs, was picked as the inspiration. Because the music was so well-matched to the campaign, it drew listeners' attention to the message in an emotive and impressionable way, thereby increasing sales. It can be seen that in order for the company to get all customers from all levels, they decided to make the advert in a way that the low class, non-educated and even the educated could understand and relate to the advert. 
In our considered opinion, the pidgin aspect of the advert was not necessary considering that the Nigerian indigenous languages had already been used to catch the non-educated and the middle class audience; a language of wider communication such as standard English should have been used instead of the pidgin in order to get the well-educated captured in the targeted audience.

\section{NEC's Advertisement on Voters' Registration}

Go dea, dem de weit fo yu o! Go nao an rejista o! Na onli wen yu regista Yu get rait to vot. Yo vot na im bi yo pawa o.

Di senta dem de opin efri-de-bai-de from et o'klok fo di moni go rish sis o'klok fo ifinin from Monde etin March, go rish Monde twenti-faif 2015. Na di National Eletora Komishon se mek wi kari dis tori rish yo domot ooo. Your vote da your hand ooo.

(Source: Radio Nigeria 3, WAZOBIA FM 93.5, March 2015)

\section{Translation}

Please go there, they are waiting for you! Go and register now! It is when you register that you have the right to vote. Your vote is your power! The Center opens every day, from 8 o'clock in the morning to 6 $O$ 'clock in the evening, from Monday 18 to Monday twenty-five March 2015.

This advert belongs to the National Electoral Commission designed to motivate voters to turn up in high numbers to register. It was aired nationwide in Nigeria, using all the media. The advert is supposed to reach everybody in Nigeria. We have presented the location of the adverts target audience; we proceed with the body that produced the advertisement. Nigeria's NEC is the body charged with the conduction of elections in Nigeria since 1998. They have over the years produced several English, Hausa, Igbo and Yoruba advertisements. NEC has equally produced adverts in NPE in the past; therefore, this is not their first outing. Coker and Oke claim (4) that among NEC's numerous pidgin adverts, this particular text generated the most momentous consciousness amid Nigerians at the grassroots level. We cannot independently confirm or refute this claim but what we can say is that the Nigerian Pidgin aided in getting the message to the target audience. However, here are the inconsistencies observed in the pidgin advert:

First, the word register is spelt inconsistently as in 'Go nao an rejista o!' versus 'Na onli wen yu regista'; secondly the word 'vote' is spelt conflictingly 'Yu get rait to vot' versus 'Your vote da your hand ooo'. The likely reason for this problem is because of the lack of familiarity with the orthography of Nigerian Pidgin English. This is not because there isn't an orthography in place, but the person(s) commissioned to do the advert never took the pains to check up the approved orthography. A simple rule of consistence would have been observed in these examples. If you spelt one word this way the first time, why switch to the next a second time?

Secondly, the words 'yo' and 'your' as in 'Yo vot na im bi yo pawa o' versus 'Your vote da your hand ooo' are supposed to be the same word in the said advert. To say the least, those meant to read this advert would have the whole day to figure out that the two words are to be 
pronounced alike and mean the same thing. The first question is, who has that time to waste trying to make out the meaning of an advert? Why not decide at the outset which spelling serves you the best? These irreconcilable spellings pose lots of problem to the target audience.

Thirdly, in the same pidgin advert the time is spelt out in words as in 'et o'klok', 'sis o'klok', the dates are also spelt out in words as in 'etin' and 'twenti-faif'. One wonders why the time is not in Arabic numeral as the English translation demonstrates, which is eye catchy, easy to read and to remember, for instance, from ' 8 o'clock' to ' 6 O'clock', and from Monde 18 to Monde 25 .

Fourthly, the word 'they' is spelt differently in the advert as '...de weit fo yu o!' and the other as '...da your hand ooo'. This kind of error semantically impinges the meaning intended in the advert. It takes several readings for the reader to realise that they are actually one word spelt differently. Lastly, the spelling of the word 'money' and 'morning' is one and the same; both are spelt 'moni'. These words are homophones in pidgin but with distinct meanings, it takes time to figure out each time one of the words comes up what the meaning is. This gives the reader unnecessary linguistic headache.

While we would not stop organizations and/or individuals advertising in pidgin, we simply advocate the need for improvement in the writing and the design of the adverts.

\section{Money Transfer}

(Source: UBA's Money Gram, on WAZOBIA FM, September 2021)

Speaker A: If na moni fo skul, o ospita bil; weda na moni fo haus, o serimoni; if na moni fo chop, o tu bai haus; kontakt obodo Oyibo, an yo moni go land, expres!

Speaker B: (Many Voices) UBA Moni Gram!

Translation:

Speaker A: If it's school fees or hospital bills; if it's to build a house, or social events; if it's money for upkeep or mortgage, ask your relatives to transfer funds to you from abroad and you'll receive your money promptly!

Speaker B: (Many Voices) UBA Money Gram!

We intend to examine the word 'moni' and the suffix 'moni' as used in this advert. In the first instance the word moni means 'money', but we do not understand the meaning of the suffix 'moni' in the word 'serimoni'. We suggest that money would have been spelt 'munee or monee', and the suffix spelt 'moni'. In this way, the frustration of readers trying fruitlessly to decode the meaning of the expressions would not have been necessary. For an advert where certain expressions are either meaningless or ambiguous, the intended effect is lost on the target audience. The second problem with this advert is the repeated use of [o] 'or'; NP orthography differentiates between 'o', ' $\rho$ ' and ' $0:$ '. The correct letter for that advert is ' $0:$ ' spelt $\partial \dot{\partial}$ 'or' and not 'o'. 
This advert was aired on WAZOBIA FM, a radio station that the elite group does not tune to. The target audience, we suppose, are the upper class, middle class and educated elite. In our opinion choosing to air it in pidgin is like making an advert for the wrong target audience, as the target audience here might not really pay attention to get the message in the advert, considering it's being aired in a language they assume to be low class and beneath them, even if the ad is humorous in nature. In other words, we posit that people who would want money for the listed items above might not be listening to WAZOBIA FM. They are the upper class cum middle class, who speak the very best of English. The language used here is repugnant to them. The question is, why spend so much money on an advert that targets the wrong people? Of course there are those who will equally argue that the low class also needs these items and they might contact their relatives abroad to send them money. This might be so, but the number that falls into this group is infinitesimal.

\section{Glo Advert}

A man sleeping and making tricycle (keke) sounds, and falls off the wooden chair he is sitting on:

Speaker A: u don get keke before, wa you da mak sound like keke, comon gwo an wash dat plat

(The man wakes up from his dream angry that it was only a dream)

Speaker B: tak dis 200 naira go by recharge card u fit win bru bru (laughs)

(Man receives a message and has won a keke; he suddenly shouts and run off)

Voice over: Just recharge 200 naira and win oghonge prices, from generator to keke, to laptop, grinding machine and plenty plenty prices.

This advert is done in pidgin and also in creole; the pidgin spoken in the Northern part of Nigeria is a creole, and this advert is done in creole by Jarumi K, a northern actor. Also available is a version of this advert in Nigeria Pidgin as well as Standard English. Our analyses are presented below:

a. wa you da mak sound like keke

The first problem with this utterance is the word 'wa'; we suppose that the intended word is 'wai' but out of carelessness or lack of knowledge, the person misspelt the word. It took us a while to figure it out because the reading did not make sense. The second is 'da'. We presume that the intended word is 'de'-again the problem of spelling pidgin words inconsistently.

b. comon gwo an wash

The next problem is the word 'gwo' is it 'go' or what? The time it takes for a reader to figure out the meaning of the word, and the transient nature of advert, it becomes problematic to grasp the intended meaning. It is not as if Nigerian Pidgin cannot be used 
with precision, it can. It takes just a little imagination and creativity to achieve it. If the worst comes to be, consult the Pidgin orthography.

c. wash dat plat

It is clear that the word 'plat' means 'plate'. This is because the initial word wash in the same sentence disambiguates it. The pidgin word 'plat' could mean 'weave' a ladies hair, or 'plant' yam or cassava in a farmland. The word is ambiguous; a modification of the spelling, e.g., 'pleit' would have resolved the ambiguity.

d. tak dis 200 naira go by recharge card

In (b) above, 'go' is spelt as 'gwo' but here it is spelt 'go'. Doing these in the same piece of advert is annoying to say the least. What happened to consistency of presentation? Spelling the same word the same way all the time is one of the principles of good orthography. Secondly, writing 'by' for 'bai' is outrageous. Although some people will figure it out sooner or later, it is not necessary to treat your audience to such violence when it can be avoided.

e. $\quad \mathrm{u}$ fit win bru bru

The word 'bru bru' has no meaning whatsoever; if it does we do not know; it does not contribute to the general meaning of the advertisement. This is taking the target audience for an easy ride on a broken roller coaster, anybody could fall off at any time and break a rib or two.

f. win oghonge prices

The problem here is the word 'oghonge'. In the advert, it is pronounced 'ogbonge' but spelt oghonge-wrong spelling at the very best or an entirely different word at the very worst. Situations like these are what we are canvassing against in this paper.

\section{Coca-Cola Advert}

A man is seen in a bar sealing coke bottles, a child comes in to buy, but notices the seller is a member of another football club through his jersey so he challenges him to a banter by saying "we go bit una latter". The word 'bit' in pidgin doubles for Standard English 'bit' and 'beat'. 'Bit' in this scenario means his club will win, but the use of 'bit' is ambiguous in this sentence. It could imply to attack something or somebody repetitively cum pugnaciously with intent to cause harm or injury, characteristically using a gizmo like a weapon or lash (as a verb). It could also denote to conquer (someone) in a sport, fight or in other competitive circumstances (as a verb). It could suggest a key pronunciation or recurring pattern of music or poetics, for instance, "the glissando begins on the second beat" (as a noun). It could denote the flustering of the wings of bird's in flight, as in "the beat of the swallow's wings as they dive after midges" (as a noun). It could mean completely exhausted, as in "I'm beat, I need an hour or so to rest" (as an adjective). It could relate "to the beat generation or its philosophy", as in "beat poet Allen Ginsberg" (as an adjective). With these multiple understandings, the simple expression "we go bit una latter' spirals out of hand. For an advert, nothing needs to get out of control, especially meaning. 


\section{Panadol Extra}

This is an advert showing a strong man who owns a factory where he melts and makes iron related products alongside his workers. Due to stress, he gets a strong headache that won't let him work, and with the intervention of Panadol extra, he is treated for the headache. With a catchy pidginized phrase like 'panadol extra come hammer the strong strong headache', it can be said that the choice of words in the advert create room for ambiguity, as hammer in Standard English means something entirely different from the meaning realised in the advert. Although the pidgin used in this advert is humorous, we personally feel it makes the message being passed on look unserious, and the product looks and sounds inactive as the concentration of the advert is more on the humorous part of the message than on the medical message and product being sold.

\section{MTN Lumos Advert}

This is an animated themed advert; it shows how a man suffers from the different "wahala" that comes with running a generator and the poor electric system we have in Nigeria, then Lumos MTN yellow box swings in to save the day. Let us analyse this pidgin advert:

If you wan make life beta for you, then you go shift come the beta life with mtn lumos yellow box, for just 20 thousand naira, I don save money, save time, no more fuel wahala, no more electrician and mechanic wahala, join me now ooo bfor them finish, come and enjoy the good life.

First, this advert uses animation. In Nigeria, most people think that animation is for kids - the same reason adults in Nigeria do not watch Cartoon Network. They feel the subject matter is beneath them. The essence is to get children away from trouble, keep them busy, and perhaps in the process, get them to learn one or two things. Therefore, the use of animation in the advert drops the level of seriousness of the advert. Next, the advert is misleading. MTN Lumos yellow box is not strong and powerful enough for a whole household to depend on it to a point where they do without a generator, an electrician, and a mechanic. The question is, how much can you really save by using MTN Lumos? It is good for recharging phones, watching television, and maybe a fan for one hour. It definitely cannot carry air conditioners or refrigerators. In other words, it does not last long without recharging. The use of Pidgin English further makes it worse. Do not forget pidgin remains a contact language and a low class language, at that. Adverts done in this language provokes a conflicting reaction most times; it takes a lot of time and energy to get the attention of a serious target audience.

\section{Travel Beta Advert}

This advert comes with a jingle, done in pidgin explaining how Travel Better helps you plan your journey to anywhere in the world, by making your experience of travelling a better one.

Travel Beta is a travelling agency which helps in planning vacation, flights, and trips for its customers. In Nigeria, flights are expensive, so doing this advert in pidgin to me is a wrong move. How many low class people or uneducated people can afford travelling with flight? Their target audience and choice of language is totally wrong. 


\section{Indomie Advert}

An indomie advert dated 2012, where a grandmother knocks at the door, a woman opens, she comes in and the kids are so happy to see her; the kids ask her to guess what they are eating for dinner, and the woman said "na indomi na, na so una mama been da like indomi". They show where they all finish eating and the kids start singing and praising their mother and grandmother.

This advert mixes Standard English and Nigerian Pidgin. Pidgin English is assigned to the uneducated, the grandma, while good English is assigned to the children. We approve of this approach as everybody is carried along.

\section{Shal'artem Malaria Tablet Advert}

This is a malaria tablet advert done by one of the Nigerian comedians popularly called Brother Shaggy. It shows when he walks into a pharmacy wrapped in his blanket; it turns out he is sick and down with malaria. He approaches the pharmacist and asks to be given the same tablet he was given the last time. He is then given the tablet.

Voice over: "No let malaria kill you o, wen malaria show face, knack am with shal'artem, no let malaria comot action for your body ooo."

The pidgin used in this advert makes the message against malaria sound unserious. Everyday, people die of malaria. It is a very serious ailment in Nigeria. This advert would have employed many indigenous languages besides Pidgin and English because nobody is really free from malaria. Pidgin is humorous, and the use of a comedian in the advert, we think, kills the seriousness in the message being passed across.

\section{CONCLUSION}

It can be said that pidgin and creole are global languages and they are no longer looked at as low class languages, especially with the existence of creoles, even people of different classes are seen listening and enjoying adverts in pidgin and creole. All classes of people seek to understand the perception of broadcast media audience towards the use of Pidgin English in dissemination of adverts messages and as a language of popular communication especially as regards to advertisements. Notwithstanding, it is very important for marketers and the media personnel to put demography and the cost of the production into consideration when picking the language for an advert, as the cost of a product will determine its target audience. From the examples above, we draw certain conclusions. This paper elucidates and evinces "how and why Pidgin adverts communicate the intended meaning of their advertisers and how the audiences perceive them", as seen above, some of the adverts are ambiguous in nature, some do not target the right audience, while some send the wrong message. The usage of pidgin in advertisements has its advantages and disadvantages, especially when directed to the wrong audience. 


\section{REFERENCES}

Akintayo, A. 'Emergent trends in the use of pidgin in television advertisements'. Management Trends, 2, 1: 162 - 182. 2008. Print.

Awonusi, V. 'Politics and politicians for sale: an examination of advertising English in Nigeria's political transition programme’. Studia Anglica Postaniensia. 07-129. 1996. Print.

Coker, O. \& Koe, R. Arts for ad sake: advertising language as literary language in selected advertising copy in Nigeria. The African symposium: an online journal of the African educational research work. 12 (2) (Retrieved 30 August 2021). Online.

Crystal, D. The Cambridge encyclopaedia of language $3^{\text {rd }}$ ed. Cambridge: Cambridge University Press. 1995. Print.

Dada, S.A. 'Stylo-rhetorical devices in Pidgin English advertisement in Nigeria'. Research Journal of English Language and Literature (RJELAL), 1 (1), 35-41 2013 Print.

Elugbe, B. \& Omamor, A. P. Nigerian Pidgin: Background and prospects. Ibadan: Heinemann Educational Books Nigeria Plc. 1991. Print.

Elugbe, B. Nigerian Pidgin: problems and prospects. In A. Bamgbose, A. Banjo, \& Thomas, A. (Eds.) New Englishes: A West African perspective (284-289). Ibadan: Mosurp Publishers and Bookseller. 1995. Print.

Hall, R. A. Pidgin and Creole Languages. Ithaca 1966

Okwechime, C. Essentials of advertising in Nigeria ( $2^{\text {nd }}$ Edition). Asaba: Prime Legacies Limited. 2009. Print.

Oribhabor, E. The use of Naija in the media, arts and entertainment. Proceedings of the conference on Nigerian pidgin, University of Ibadan. 2010. Print.

Todd, L. Language and society, London: Routledge and Kegan Paul Ltd. 1974. Print. Wikipedia, Nigerian Pidgin English. English-based Pidgins (Retrieved August 2021) Yinka, I. Nigerian harnesses Pidgin English power. (Retrieved August 2021) 